\title{
The First International Electrodeposition Conference
}

$\mathrm{I}^{\mathrm{N}}$ $N$ opening the first International Electrodeposition Conference, which was held at British Industries House, London, on March 3-4, Lord Melchett referred to the rapid advance which has been made in recent years in the science and practice of electroplating and other electrodeposition processes, and paid a tribute to the work of the Electrodepositors' Technical Society in furthering these developments and in organizing this first International Conference.

In the four sessions of the Conference, which were presided over by Mr. A. E. Ollard (president of the E.T.S.), Mr. C. Francis Carter, Mr. D. J. Macnaughtan and Mr. S. Field respectively, practically every aspect of electrodeposition was discussed. Four general papers by M. M. Ballay (France), Mr. E. J. Dobbs (Britain), Mr. G. B. Hogaboom (United States) and Dr. R. Springer (Germany) provided surveys of current practice and tendencies in the authors' respective countries. As would be expected in view of the present wide dissemination of ideas and information through the medium of scientific and technical publications, differences in practice between various countries are mainly those arising from differences in public taste and range of demand, or from differences in availability of certain materials. Thus, preference in Great Britain for cadmium plate with a matte surface has limited the use of baths for the direct production of bright cadmium deposits, which are largely operated abroad. Shortage of certain nonferrous metals in Germany has led to the development of improved methods for electroplating on aluminium; to the more extensive use of anodized aluminium ; to the use of insoluble anodes in nickelplating baths, the composition of which is maintained by additions of nickel carbonate, or to the production of nickel anodes by electrodeposition from such baths on lead strip; and to the elaboration of methods for producing firmly adherent electrodeposits on articles of non-metallic composition such as bakelite and celluloid, which are so successful that they will undoubtedly retain their importance when normal supplies of metal become available.

Annong special features of technique, particular reference was made to the 'copper degreasing process' employed mainly in France. M. A. Chabany (France) showed that this process, which consists of cathodic treatment of the basis metal in an alkaline cyanide solution containing copper, so that degreasing is accompanied by copper deposition, needs slight modification when applied to zinc surfaces. Loss of cyanide from the solution during operation is attributed to its oxidation to cyanate.

In the United States, Germany and Great Britain, rapid advances are being made in the development and utilization of 'automatic plant', in which articles of standard shapes and sizes are carried by means of conveyor ehains through a succession of tanks in which preliminary cleaning operations, electrodeposition, and certain finishing processes are carried out, ench for predetermined times. One automatic nickelplating plant in Great Britain is using 12,000 amperes and turns out more than a million articles per week. Dr. J. Kronsbein (Britain) described a new type of antomatic plant for njckel deposition in which the work bars are transferred from tank to tank by means of electromagnets, with arrangements for varying the time occupied in the transfer ; and a novel chromiumplating plant in which the articles to be plated are held on the periphery of a magnetized double-disk wheel which revolves on a horizontal axis and thus carries the work through the plating solution. In Germany and the United States, electrolytic 'gal. vanizing' of wire is carried out on a large scale: sixty large plants in Germany consume about 300,000 amperes. Electrotinning of steel strip is practised in Germany, and is in course of commercial development in the United States.

The possibility of electrodepositing nickel and then chromium in a single automatic plant has been difficult to realize owing to the necessity for polishing the nickel undercoat before depositing chromium on it. Much attention has therefore been given to the direct deposition of 'bright nickel', and several types of plating bath for this purpose are now in operation. Dr. Schlötter's solution, which contains aromatic sulphonic acids, and baths with other organic addition agents are widely used, but several speakers stressed the value of the nickel-cobalt type of bath, which is claimed to give deposits equal in physical characteristics to an ordinary nickel doposit and to be the only bright nickel solution which can be completely controlled by chemical analysis. Methods for the production of bright deposits of several other metals are in use, and Dr. B. Egeberg and Mr. N. E. Promisel (United States) described the principles of a method which they are developing for evaluating the relative brightness of electrodeposits.

The introduction of simple and reliable tests for adhesion, porosity, thickness, and corrosion resistance of electrodeposits is making it possible to lay down specifications for plating to meet various conditions of service. Several contributors gave examples of such specifications which have been adopted by certain industries in their respective countries, and some speakers directed attention to the importance of specifying the minimum thickness required on 'significant surfaces' instead of or in addition to the average thickness over the whole article. Examples of the extent to which the thickness of silver plate may vary on various parts of the surface of articles of specified shapes were furnished in the survey of silver-plating practice presented by Mr. F. C. Mesle (United States).

Papers dealing with the development and practice of electrodeposition of particular metals were also furnished by Dr. G. Soderberg (United States) for cadmium from cyanide baths; by Mr. R. H. Atkinson (Britain) and by Messrs. E. C. Davies and A. R. Powell (Britain) for platinum; by Mr. H. W. J. Pope (Britain) for gold; and by Dr. K. Schumpelt (United States) for the platinum metals--especially rhodium. Electrodeposited platinum and palladium are considerably harder than the corresponding rolled metals, and the hardness of electrodeposited platinum and rhodium is exceeded only by electrodeposited chromium. Owing to its exceptional resistance to attack by most chemical reagents and its fine white lustre, rhodium plating is applied not only to jewellery and as a non-tarnishing coating on silver ware, but also with considerable success to reflectors: it is 
unaffected by carbon particles sputtered from arc lights.

By means of a specially devised technique, Mr. A. W. Hothersall (Britain) showed that the adhesion of electro-deposits to nickel surfaces may be notably decreased by the presence of an invisible oxide film on the latter, and for securing the highest adhesion he recommended anodic etching of the nickel in sulphuric acid solution, the current being finally reversed for a moment. The special difficulty in securing adhesion of electrodeposits to chromium and its alloys is also due undoubtedly to the presence of an oxide film, and in order to overcome this $\mathrm{Mr}$. G. E. Gardam (Britain) recommended cathodic treatment of the degreased surface in strongly acid nickel sulphate solution at high current density, which causes simultaneous removal of the film and deposition of nickel. It is advantageous to deposit a layer of copper (from the acid bath) on the resulting surface before plating with nickel from the regular nickel bath.

M. P. A. Jacquet (France) has established that whereas on a practically amorphous copper surface, produced by mechanical polishing, electrodeposition of copper begins from randomly distributed nuclei ; a surface which has been electrolytically 'smoothed' by his method of anodic treatment in phosphoric acid retains its original crystal grain structure, and this structure is continued when copper is electrodeposited on it from the acid bath. In the initial stages of deposition, the deposit forms preferentially on grains which are favourably orientated with respect to the surface, and the character of its growth is affected by this orientation. Modifications of the phenomena observed when 'aged' baths are used are attributed to the presence of cuprous ions.
The various modifications of the crystal structure of electrodeposits which may arise through inclusion in the deposit of substances added to the bath (addition agents) or of insoluble substances formed in the solution adjacent to the cathode surface, were shown in a remarkable series of photomicrographs presented by M. M. Cymboliste (France). Such inclusions are classified with reference to their character, origin and effect on the structure and properties of the electrodeposit; and the effects of varying the conditions of electrolysis are interpreted in terms of the influence of these conditions on the formation of inclusions. Prof. A. Phillips and Mr. W. R. Meyer (United States) reported results of an investigation of the upper limits of current density at which copper deposited from the acid bath on a copper surface ceased to continue the structure of the basis metal. From the cyanide bath no such continuation of strueture was observed even at very low current densities. Even minute traces of lead in the acid copper bath were found to affect the character of the copper deposit, tending to make it dense, bright and somewhat brittle; but notable amounts of zinc in the bath scarcely affected the structure.

Papers by Dr. N. A. Isgarischev (U.S.S.R.) and by Prof. A. Glazunov (Czechoslovakia) and Dr. M. Schlötter (Germany) dealt with the mechanism of deposition of metals from complex salt solutions; and contributions from Prof. L. S. Ornstein in collaboration with B. Baars and P. J. Haringhuizen (Holland) were concorned with a comparison of the behaviour of electrodeposited and evaporated metallic films towards corrosive agencies, which had been investigated by means of a specially devised optical method.

\section{Permanence of Oceanic Basins and Continental Masses*}

$\mathrm{I}^{\mathrm{N}}$ his presidential address to the Geological Society of London in 1870, Huxley brought into correlation with geological science the scheme of zoological provinces which he had proposed to the Zoological Society two years before. He recognized the fact that the distribution of life, as then known, implied "a vast alteration of the physical geography of the globe", but he nevertheless conformed to the orthodox view of the time regarding the persistence of a general uniformity in the positions of the four great oceans from Devonian or perhaps earlier times.

That the oceanic basins and continental masses had, from the earliest geological times, occupied their positions, with little more than marginal changes, was an idea that originated in its geological bearing with J. D. Dana in 1856. Taken in conjunction with the then prevailing notion, developed by W. Hopkins, that the earth was solid to great depths, the doctrine of permanency persisted for many years unchallenged ; it is still held by many geologists in an attenuated form.

After the publication of the "Origin of Species" in 1859, showing, in the words of Darwin, that "each species has proceeded from a single birthplace", the distribution of animals and plants became a critical test of the validity of the doctrine of permanency. Edward Forbes had challenged the idea, but Darwin

- Summary of the Huxley Memorial Lecture delivered by Sir Thomas Holland, K.C.S.r., F.R.S., on May 4. considered that, when he wrote in 1859, we knew very little about the strange accidents by which living beings secured transport over oceanic barriers; and accordingly he, followed by Lyell in 1868, considered that Dana's views could not justifiably be put aside.

W. T. Blandford, however, speaking as president of the Geological Society, twenty years after Huxley, with far more extensive data at his command. demonstrated that the distribution of animals and plants could not be explained without the previous existence of land surfaces across regions now occupied by oceanic deeps. Although Blandford at that time confined himself to arguments based on biogeography, his previous work in India had led him independently to the same conclusion regarding the southern oceans. It was Blandford who discovered in 1856 the glacial beds at the base of the Gondwana system of 'continental' rocks in India. Later work in the southern continents led to similar discoveries, and ultimately established a correlation between India, Australia, Africa and South America.

So long ago as 1879, Blandford pointed out, in the official "Manual of the Geology of India", that the fossil plants and land animals of the Gondwana system in India were related so definitely to those on the southern continents that land connexions must have existed at certain times, if not continuously, between these areas across the positions now occupied by the 